\title{
The need for and the impact of a family-centred intervention for parents of children with developmental disabilities: A model project in rural Ireland ${ }^{\dagger}$
}

\author{
Roy McConkey ${ }^{*}$, Pauline O'Hagan ${ }^{2}$ and Joanne Corcoran ${ }^{2}$, \\ 1 Ulster University, N. Ireland, UK; r.mcconkey@ulster.ac.uk \\ 2 Positives Futures, N. Ireland, UK; pauline.ohagan@positive-futures.net; joanne.corcoran@positive-fu- \\ tures.net \\ * Correspondence: r.mconkey@ulster.ac.uk
}

Publisher's Note: MDPI stays neutral with regard to jurisdictional claims in published maps and institutional affiliations.

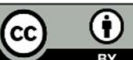

Copyright: $\odot 2021$ by the authors. Submitted for possible open access publication under the terms and conditions of the Creative Commons Attribution (CC BY) license (http://creativecommons.org/licenses/by/4.0/).

\begin{abstract}
Parents of children with developmental disabilities are at greater risk of poor mental health and social isolation. An innovative, family-centred support service involved project staff visiting the family home every two weeks for around one year. Thus far 85 families have participated and at the start a majority of parents had below average scores on a standardised measure of parental well-being and low participation in social and community activities. At the end of their time on the project, significant increases in parental well-being scores were reported but with limited impact on their social participation. Covid 'lock-downs' in recent months may have contributed to the latter. The project is an example of how social care provision for families could be transformed even in rural areas at a relatively low cost.
\end{abstract}

Keywords: Developmental disabilities; family-centred; parents; social isolation; rural; emotional well-being.

\section{Introduction}

Parents of children with developmental disabilities are at greater risk of poor mental health and social isolation that is compounded by family circumstances, living in rural settings and the recent Covid-19 pandemic [1]. Often little personal support is available to parents. Family-centred interventions have been endorsed internationally for promoting children's development as well as enhancing parental wellbeing [2]. Yet current service provision is predominately child-focused and clinic-centred. Often it is focused on more affluent and better educated parents living in urban settings [3].

This paper describes the development and evaluation of an innovative, family-centred support service in a rural county of Ireland provided by an NGO called Positive Futures. The two aims were: 1) to enhance the children's social and communication skills and promote their participation in community activities, and 2) to provide emotional support to parents and extend their social actives and networks.

\section{Materials and Methods}

Locally recruited project staff visited the family home every two weeks for around one year, although during Covid lockdowns in 2020 'visits' had to be delivered by phone or through Zoom. Developmental goals for the child with various developmental disabilities were agreed with parents alongside actions to address the expressed needs of parents and siblings. Community activities were identified or created to promote the social inclusion of the child and family in local communities. A mix of home-based learning activities took place in the family home alongside outings for the children to leisure and sport activities in the local community. In addition, social activities were organized mainly 
for mothers but also for fathers and siblings. Opportunities for families to meet each other socially were also arranged. The project has been operational for four years and each year around 25 children are enrolled.

\subsection{Description of the participants}

In all, 97 children from 85 families have been involved with the project to date; representing $89 \%$ of families referred to the project. Over half the families $(58 \%)$ resided in areas that fell within the top $30 \%$ of more deprived areas in Northern Ireland with only $4 \%$ living in the $30 \%$ least deprived areas. Both natural parents were present in 59 families $(69 \%)$ and a further two were a reconstituted family $(2 \%)$ while $24(28 \%)$ were lone parents. In all but five families, the mothers were the child's primary carers. Two-thirds of primary carers $(n=56)$ were not in employment while $11(13 \%)$ worked full-time, 15 $(18 \%)$ part-time and two occasionally $(2 \%)$. The median number of children in the household was two (range 1 to 7 ). In all, 25 (33\%) families reported having another child with a disability.

The median age of the child when starting the project was 6.3 years (range 11 months to 13 years). In all, 54 (54\%) were reported to have autism; 30 (31\%) had learning disabilities and $27(28 \%)$ with developmental disabilities. Over one third of children (36\%) attended a mainstream school with a further $18 \%$ attending a preschool or nursery. Also $39 \%$ attended a special school or special unit. The learning targets for the children were grouped into these domains: social skills; communication skills; promoting independence; confidence building; community engagement and personal care.

\subsection{Parental assessments}

Parents reported on the various social activities they personally had participated in either during the past month, occasionally, never or had not wanted to do this activity. Comparisons can be made with the leisure activities of a representative sample of adult persons in Northern Ireland (available at: https://www.ark.ac.uk/nilt/results/sportres.html).

The wellbeing of the primary carers was assessed in two ways. First, carers were asked to complete a standard questionnaire: Edinburgh-Warwick Mental Wellbeing Scale [4]. This consists to 14 items with five response categories and total scores can be compared to ratings given by the general population. Second, a newly developed measure for use with parents of children with developmental disabilities assesses their subjective wellbeing. This consisted of eight items and parents rated themselves using a 10-point scale [5]. Four additional items specific to this project were added.

These measures were self-competed by parents at the start of their involvement with the project and towards the end of their time which was around 12 months later. In addition, parents' reactions to the project were obtained using a structured self-completion questionnaire which was supplemented with phone interviews with seven parents.

\section{Results}

\subsection{Baseline assessments}

Table 1 contrasts the number and percentage of parents who took part in the activities listed at least once a month compared to the percentage in a representative sample of the adults in Northern Ireland. 
Table 1. The number of parents involved in social activities $(n=85)$ compared to the NI population.

\begin{tabular}{ccc}
\hline During the past year, have you: & Project Parents & NI \% \\
\hline Had friends/family come to house for coffee/meal etc & $19(22 \%)$ & $75 \%$ \\
Been to cinema, theatre, concert & $10(12 \%)$ & $15 \%$ \\
Attended gym, sports, exercise class & $10(12 \%)$ & $72 \%$ \\
Been to church/church activities & $7(8 \%)$ & $30 \%$ \\
Been a volunteer helper & $10(12 \%)$ & $11 \%$ \\
\hline
\end{tabular}

In addition, $58 \%$ of families had never taken a holiday in the past year compared to $23 \%$ of adults in Northern Ireland.

On the Edinburgh-Warwick Mental Wellbeing Scale, in comparison with those of the UK adult population: $17 \%$ of parents had very low scores; $39 \%$ had below average scores; $43 \%$ had average scores and only one person scored above average.

The ratings that parents gave to the subjective wellbeing items varied widely but the mean scores (out of 10) were lowest on not taking part in the local community (3.3); worrying about the child's future (4.0) and spending most of time in the house (4.3). Most parents scored highest on enjoying looking after the child (7.6) and the family getting on well together (7.5).

On these three indictors there were no statistically significant differences $(p<0.01)$ by age of parents, their marital status, area of deprivation; family income; number of children in the family and attendance at special education.

\subsection{Parental targets achieved}

In addition to monitoring the achievement of the targets set for the children (details are available on request), the specific targets that were set for each family were regularly reviewed in discussion with the families during their time with the project. The targets were grouped under the broad categories shown in Table 2. The number of families whose targets were judged to have been 'fully achieved' is shown at the six-month, ninemonth and 12 month reviews. (Note: Targets were also rated as 'partially achieved' with very few rated as 'not achieved' thus the figures shown in the table are a conservative estimate of progress. Also new targets could be set for families and siblings in the 6 to 12 months period.)

Table 2. The number and percentage of families in target areas and progress at three time points\#.

\begin{tabular}{cccc}
\hline Family Target Area & $\begin{array}{c}\text { Progress at 6 months } \\
\mathbf{( N = 7 3 )}\end{array}$ & $\begin{array}{c}\ldots \mathbf{9} \text { months } \\
\mathbf{( N = 6 8 )}\end{array}$ & $\begin{array}{c}\ldots . \mathbf{1 2} \text { months } \\
\mathbf{( N = 4 6 )}\end{array}$ \\
\hline Parents involved in Community Activities & $27 \%(18 / 66)$ & $52 \%(30 / 58)$ & $57 \%(27 / 47)$ \\
\hline Greater knowledge and skills of parents & $17 \%(10 / 60)$ & $46 \%(23 / 50)$ & $45 \%(17 / 38)$ \\
\hline Increased confidence and resilience of parents & $20 \%(11 / 54)$ & $47 \%(19 / 40)$ & $58 \%(18 / 31)$ \\
\hline Parents better able to cope with situations & $34 \%(17 / 50)$ & $60 \%(27 / 45)$ & $74 \%(23 / 31)$ \\
\hline Increased resources and tools for parents & $35 \%(17 / 49)$ & $59 \%(23 / 39)$ & $44 \%(14 / 32)$ \\
\hline Social opportunities within sibling groups & $34 \%(13 / 38)$ & $84 \%(27 / 32)$ & $89 \%(24 / 27)$ \\
\hline Respite/Fun activities for siblings & $73 \%(11 / 15)$ & $80 \%(12 / 15)$ & $84 \%(16 / 19)$ \\
\hline
\end{tabular}

\# The figures in brackets are as follows: the denominator is the number of families for whom that category of target was selected and the numerator is the number of families whose target had been rated as 'fully achieved'. As the project is ongoing, the number of families available at each review decreases. .

The parents' involvement in community activities was the most commonly targeted area in which the project worked with parents. As the Table shows, the percent of families whose targets were fully achieved rose over the family's engagement with the project particularly in the final six months. However, with a sizeable number of families their targets had only been partially achieved. Nonetheless, the targets in relation to siblings were more likely to be fully achieved. Sibling engagement was evident from the early months of the project. In addition, with a small number of families the project gave 
sibling support so that the parents could have a night out and they also investigated postschool options for a child.

\subsection{Impact of the project on parents}

By the end of September 2020, 46 families had completed their time with the project and the questionnaires used at the baseline, were repeated and completed by 42 families (91\% completion).

The number of social activities in which parents engaged both monthly or occasionally was rechecked at the end of the project. For 41 parents there was a slight but nonsignificant decrease in the number of activities in which they had engaged in either monthly or occasionally from a mean of 6.9 to 6.3. In all 20 families had reported an increase, 18 a decrease and three remained the same. However, Covid restrictions had curtailed social activities for parents who had completed their time on the project from March 2020 to the present.

On the Edinburgh-Warwick Wellbeing Scale, the parents had significantly increased scores exiting the project compared to the scores at the start (Mean $50.1 \mathrm{v} 40.0)(\mathrm{t}=5.76: \mathrm{df}$ 40: $\mathrm{p}<0.001$; Cohen's $\mathrm{d}=0.899$ ) which is indicative of a large effect size. At the start, 23 (56\%) of the 41 parents who completed the scale had below average or very below average scores but on exiting, 15 had moved to average scores, four to above average scores while only four remained below average.

For subjective wellbeing items, at the start of their involvement with the project, the mean score for 42 parents was 65.3 (range 30-109) and at the end it was 85.5 (range 55-112) from a possible range of scores from 12 to 120 . This difference was both statistically significant with a large effect size ( $t=6.38$ : $\mathrm{df}$ 41:p<0.001: Cohen's 0.985). In all, 17 parents had average scores of five and below on the 12 items prior to the project which would be indicative of poorer wellbeing but all but three of these parents scored above 5 on all items at the end of the project.

\subsection{Parental and staff reactions}

At the end of their time on the project, parents were asked to complete anonymously a brief questionnaire that summarised their experiences of the project. In all 30 questionnaires were returned. In addition, seven parents agreed to be interviewed by the first author. Also interviews or self-completed questionnaires were completed with project staff $(\mathrm{n}=6)$ and service personnel who had referred families to the project $(\mathrm{n}=5)$.

Five recurring themes featured in the responses which were analysed using thematic content analysis and these are summarised in the Figure below. The family-centredness of the service was the dominant theme that underpinned the four other themes. The confidence of parents in managing their child had increased alongside the children developing new skills and both they and the family becoming more connected with community activities. The staff provided information, tangible and emotional support to the family and developed trusted relationships with the child and mothers especially. Recommendations for improvements to the project came mainly from staff although parents would have liked the support to continue for more than 12 months. Fuller details are available on request. 


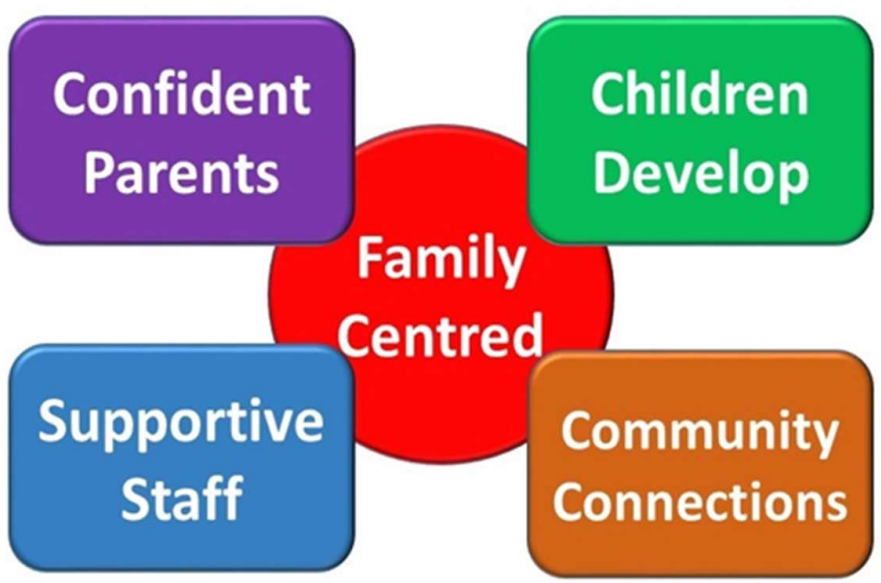

Figure 1. The main themes in parents' reactions to the service.

\section{Discussion}

The project has several achievements to its credit over the four years it has been operating. Over 100 referrals of children were made with only six families $(6 \%)$ declining to take part or withdrawing. The families come from across the social spectrum with children having a range of special needs. Nevertheless, there is a welcome bias towards more socially disadvantaged families. The parents and the children were often socially isolated with little formal support from services other than schools. Moreover, a sizeable number of families had little informal support from outside the family. The rural setting is a major contributing factor, especially when families have no car or mothers who cannot drive. The home-based, family-centred, personalised approach adopted by the project is essential given the diversity among the parents and children even within this one small geographical area.

The majority of parents and siblings had achieved their chosen targets, particularly greater involvement in community activities, increased knowledge and skills along with more confidence and resilience. Likewise siblings were more involved in social activities. However for many parents some of their targets were only partially met which suggests that ongoing support may be necessary albeit on a less intensive basis, such as telephone and social contacts.

Most parents reported significant increases in their well-being even during the Covid lockdowns. This was confirmed using two different measures. This augurs well for increasing their resilience in coping with the challenges that come with raising a child who has developmental difficulties [7]. The personal contact that parents have with project staff, allied with the parent-focussed activities provided by the project, have likely contributed to these outcomes. Often in disability services, the focus is solely on child outcomes. Hence the project serves as an example to other services on how family wellbeing can be nurtured and its impact assessed. Nonetheless, the parents benefited to varying degrees and project staff need to be sensitive to providing the extra emotional and practical support that some mothers may require and over a longer time period.

The evaluation has its limitations. It was not possible to randomly allocate families to take part in the study so selection bias on the part of referrers might be present. Likewise there was no control for changes that may have occurred with families over the passage of time. However the recruitment of a control group of families would pose significant ethical challenges. Nonetheless the qualitative findings coupled with the quantitative changes that had large effect sizes are strong evidence that participation in the project benefited the children and families.

The benefits from family-centred approaches in childhood disability services have been confirmed in other international studies [8] yet they are not commonly used in Ireland or elsewhere. Hence the value of innovative projects such as this one lie not only in 
the outcomes they provide to families and children. More crucial is the learning that it generates as to how services can be better shaped to provide cost-effective, emotional and practical supports to families in rural communities who are faced with the challenge of raising a child with developmental disabilities. It reinforces the conceptual frameworks that have emerged in recent years which combine promotion of the child's development with the needs of parents and the wider family while taking account of the social and environmental contexts in which they live [6]. Such thinking calls for major transformation to current health and social care services internationally for children with developmental disabilities and their family. The lower costs of these innovative services allied to improved outcomes that are well evidenced suggests that the main challenges lie in changing current systems and traditional staff roles [2].

\section{Conclusions}

The family-centred service was welcomed by families living in a rural setting with a high uptake and few drop-outs. The developmental gains shown by the children from the home-based activities and engagement in community activities were complemented by higher wellbeing scores of the parents and some improvement in their social engagement outside of the home, although this had reduced somewhat due to Covid restrictions. Certain families would benefit from more sustained and ongoing contact. The model is worthy of replication elsewhere and reinforces the need for transforming health and social care for children with disabilities towards more family-centred services.

Author Contributions: Conceptualization, JC and $\mathrm{POH}$; methodology, $\mathrm{POH}$ and RMC.; formal analysis, $\mathrm{RMC}$; data curation, $\mathrm{POH}$; writing - original draft preparation, $\mathrm{RMC}$; writing - review and editing, $\mathrm{POH}$ and $\mathrm{JC}$; project administration, $\mathrm{POH}$; funding acquisition, JC. All authors have read and agreed to the published version of the manuscript.

Funding: This project: including its evaluation was funded by the UK Community Fund (National Lottery).

Acknowledgments: Our grateful thanks to the staff involved in the project and to the families for sharing their information and experiences with us.

Conflicts of Interest: RMC was commissioned by Positive Futures to supervise the information gathering and to undertake the data analysis. $\mathrm{POH}$ and JC are employees of Positive Futures.

\section{References}

1. Scherer N: Verhey I, Kuper H. Depression and anxiety in parents of children with intellectual and developmental disabilities: A systematic review and meta-analysis. PloS one. 2019 Jul 30;14(7):e0219888.

2. Sukkar H, Dunst CJ, Kirkby J, editors. Early childhood intervention: Working with families of young children with special needs. Taylor \& Francis, New York, 2017

3. Mello MP, Goldman SE, Urbano RC, Hodapp RM. Services for children with autism spectrum disorder: Comparing rural and non-rural communities. Education and Training in Autism and Developmental Disabilities. 2016 Dec 1:355-65.

4. Stewart-Brown, S. L., Platt, S., Tennant, A., Maheswaran, H., Parkinson, J., Weich, S., ... \& Clarke, A. The Warwick-Edinburgh Mental Well-being Scale (WEMWBS): a valid and reliable tool for measuring mental well-being in diverse populations and projects. Journal of Epidemiology and Community Health, 2011, 65 (Suppl 2), A38-A39.

5. McConkey R. A Brief Measure of Parental Wellbeing for Use in Evaluations of Family-Centred Interventions for Children with Developmental Disabilities. Children. 2020 Sep;7(9):120.

6. Guralnick, M. J. Applying the Developmental Systems Approach to inclusive community-based early intervention programs: Process and practice. Infants \& Young Children, 2020, 33(3), 173-183.

7. Suzuki K, Hiratani M, Mizukoshi N, Hayashi T, Inagaki M. Family resilience elements alleviate the relationship between maternal psychological distress and the severity of children's developmental disorders. Research in developmental disabilities. 2018 Dec 1;83: 91-8.

8. Mas J.M, Dunst C.J, Balcells-Balcells A, Garcia-Ventura S, Giné C, Cañadas M. Family-centered practices and the parental wellbeing of young children with disabilities and developmental delay. Research in developmental disabilities. 2019 Nov 1; 94:103495. 